Revista Brasileira de Agricultura Irrigada v.11, nº.7, p. 1975 - 1985, 2017

ISSN 1982-7679 (On-line)

Fortaleza, CE, INOVAGRI - http://www.inovagri.org.br

DOI: $10.7127 /$ rbai.v11n700665

Protocolo 665.17 - 11/04/2017 Aprovado em 19/07/2017

\title{
CARACTERÍSTICAS BIOMÉTRICAS E ACÚMULO DE FITOMASSA DA BERINJELEIRA SOB IRRIGAÇÃO COM ÁGUA RESIDUÁRIA E DOSES DE NITROGÊNIO E FÓSFORO ${ }^{1}$
}

\author{
Aldair de Souza Medeiros ${ }^{2}$, Reginaldo Gomes Nobre ${ }^{3}$, Amanda Costa Campos ${ }^{4}$, \\ Manoel Moisés Ferreira de Queiroz ${ }^{3}$, Ivomberg Dourado Magalhães ${ }^{2}$, Rener Luciano de \\ Souza Ferraz ${ }^{5}$
}

\section{RESUMO}

A água na região semiárida é um dos recursos naturais com maior escassez, sendo imprescindível o seu manejo correto e a prática do reuso. Neste contexto, propôs-se avaliar o uso de nitrogênio e fósforo junto com água residuária doméstica pós-tratada em filtro de areia com fluxo intermitente sobre os aspectos de crescimento e acúmulo de fitomassa de plantas de berinjela cultivadas em casa de vegetação no semiárido paraibano. O experimento foi conduzido no município de Pombal, Paraíba, utilizando-se o delineamento experimental inteiramente casualizado, em esquema fatorial $4 \times 4+1$, com quatro repetições, sendo quatro doses de nitrogênio ( $\mathrm{N}_{1}=0,22 ; \mathrm{N}_{2}=0,39 ; \mathrm{N}_{3}=0,56 \mathrm{e} ; \mathrm{N}_{4}=0,72 \mathrm{~g} \mathrm{dm}^{-3}$ de solo) e quatro doses de fósforo ( $\mathrm{P}_{1}=0,96 ; \mathrm{P}_{2}=1,68 ; \mathrm{P}_{3}=2,40 \mathrm{e} ; \mathrm{P}_{4}=3,12 \mathrm{~g} \mathrm{dm}^{-3}$ de solo) e irrigação com água residuária. Adicionou-se um tratamento com $100 \%$ da adubação com N, P e irrigação com água de abastecimento. A interação entre as doses de nitrogênio e fósforo não influenciou os aspectos de crescimento e acúmulo de fitomassa da berinjeleira. O aumento unitário das doses de fósforo promoveu acréscimos de $0,13 \%$ no número de folhas da berinjela quando irrigada com água residuária. A dose estimada de nitrogênio de $0,43 \mathrm{~g} \mathrm{dm}^{-3}$ e irrigação com água residuária resultou em maior altura de plantas. As maiores doses de nitrogênio promoveram decréscimos significativos sobre o acúmulo de fitomassa da berinjeleira.

Palavras-chave: adubação, reuso, Solanum melongena L.

\footnotetext{
1 Trabalho extraído da dissertação de mestrado do primeiro autor, PPGHT - UFCG

${ }^{2}$ Doutorando em Agronomia - Produção Vegetal, Centro de Ciências Agrárias, Universidade Federal de Alagoas - UFAL, Rio Largo, AL, e-mail: aldairmedeiros@gmail.com, ivomberg31@hotmail.com

${ }^{3}$ Prof. Doutor, Centro de Ciências e Tecnologia Agroalimentar, Universidade Federal de Campina Grande UFCG, Pombal, PB, e-mail: rgomesnobre@yahoo.com.br,mmfqueiroz@gmail.com

${ }^{4}$ Mestranda em Zootecnia, Centro de Saúde e Tecnologia Rural, Universidade Federal de Campina Grande UFCG, Patos, PB, e-mail: amandacampos02@hotmail.com

${ }^{5}$ Doutorando em Engenharia Agrícola - Irrigação e Drenagem, Centro de Tecnologia e Recursos Naturais, Universidade Federal de Campina Grande - UFCG, Campina Grande, PB, e-mail: ferraz340@gmail.com
} 


\title{
BIOMETRIC CHARACTERISTICS AND PHYTOMASS ACCUMULATION OF EGGPLANT UNDER IRRIGATION WITH WASTEWATER AND DOSES OF NITROGEN AND PHOSPHORUS
}

\begin{abstract}
Water in the semiarid region is one of the most scarce natural resources, and its correct management and practice of reuse are indispensable. In this context, it was proposed to evaluate the use of nitrogen and phosphorus together with post-treated domestic wastewater in a sand filter with intermittent flow on the aspects of growth and phytomass accumulation of eggplant plants grown in a greenhouse in the semi-arid region of Paraíba. The experiment was conducted in the municipality of Pombal, Paraíba, Brazil, using a completely randomized experimental design, in a $4 \times 4+1$ factorial scheme, with four replications, with four nitrogen doses $\left(\mathrm{N}_{1}=\right.$ 0.22 ; $\mathrm{N}_{2}=0.39 ; \mathrm{N}_{3}=0.56$ and; $\mathrm{N}_{4}=0.72 \mathrm{~g} \mathrm{dm}^{-3}$ of soil) and four doses of phosphorus $\left(\mathrm{P}_{1}=\right.$ 0.96; $\mathrm{P}_{2}=1.68 ; \mathrm{P}_{3}=2.40$ and; $\mathrm{P}_{4}=3.12 \mathrm{~g} \mathrm{dm}^{-3}$ of soil) and irrigation with wastewater. $\mathrm{A}$ treatment with $100 \%$ of the fertilization with $\mathrm{N}, \mathrm{P}$ and irrigation with water of supply was added. The interaction between the nitrogen and phosphorus doses did not influence the aspects of growth and accumulation of phytomass of the eggplant. The unit increase of the phosphorus doses promoted increases of $0.13 \%$ in the number of leaves of the eggplant when irrigated with wastewater. The estimated nitrogen dose of $0.43 \mathrm{~g} \mathrm{dm}^{-3}$ and irrigation with wastewater resulted in higher plant height. The higher doses of nitrogen promoted significant decreases on the accumulation of phytomass of the eggplant.
\end{abstract}

Keywords: fertilization, reuse, Solanum melongena L.

\section{INTRODUÇÃO}

A utilização sem controle da água pelo homem, para diversos fins, tem promovido escassez desse recurso natural, principalmente nas regiões áridas e semiáridas, consequentemente, limitando o desenvolvimento social e econômico das regiões (MEDEIROS et al., 2015). Buscando solucionar esse problema, alguns pesquisadores avaliam alternativas viáveis, como por exemplo, o uso de água com "qualidade inferior" na agricultura irrigada, principalmente águas salinas e residuária (OLIVEIRA et al., 2013; LIMA et al., 2015; MEDEIROS et al., 2015; NASCIMENTO et al., 2016).

Neste contexto, a berinjela (Solanum melongena L.) é uma hortaliça da família Solanáceae originada de regiões tropicais do Oriente. Possui fácil adaptação às condições de clima tropical, e pode ser cultivada durante o ano todo em regiões de clima subtropical (FILGUEIRA, 2008).

A água residuária (AR), quando tratada e usada de forma planejada, torna-se uma alternativa de fonte hídrica, sobretudo, para a região semiárida, possibilitando, a economia da água superficial e produção agrícola em regiões com restrições na disponibilidade hídrica (OLIVEIRA et al., 2014). Além de ser fonte hídrica, a AR é um potencial fornecedor de macro e micronutrientes para as plantas, principalmente o nitrogênio $(\mathrm{N})$ e fósforo $(\mathrm{P})$ (MEDEIROS et al., 2015). O N e o P são macronutrientes essenciais durante $\mathrm{O}$ crescimento e desenvolvimento das plantas, uma vez que, desempenham papéis importantes nos processos de respiração e fotossíntese (GUEDES FILHO et al., 2013; SOUZA et al., 2017).

$\mathrm{Na}$ cultura da berinjela, o $\mathrm{N}$ e o $\mathrm{P}$ proporcionam maiores respostas de crescimento e produção (FILGUEIRA, 2008), mas, pouco se conhece sobre as quantidades ideais desses nutrientes a serem fornecidas quando se utiliza AR na irrigação das plantas. Assim, objetiva-se avaliar o uso de nitrogênio e fósforo, conjuntamente com água residuária doméstica pós-tratada em filtro de areia, com 
fluxo intermitente sobre os aspectos de crescimento e acúmulo de fitomassa de plantas de berinjela, cultivadas em casa de vegetação no semiárido paraibano.

\section{MATERIAL E MÉTODOS}

O experimento foi conduzido durante o período de outubro de 2014 a fevereiro de 2015, em casa de vegetação, no Centro de Ciências e Tecnologia Agroalimentar (CCTA) da Universidade Federal de Campina Grande (UFCG), Campus de Pombal, Paraíba.

Conforme Köppen, a cidade de Pombal tem clima do tipo BSh, representando clima semiárido quente e seco.

Os tratamentos resultaram na combinação de dois fatores: quatro doses de nitrogênio $\quad\left(\mathrm{N}_{1}=0,22 ; \mathrm{N}_{2}=0,39 ; \mathrm{N}_{3}=0,56\right.$

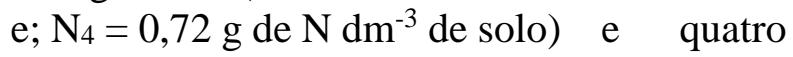
doses de fósforo $\left(\mathrm{P}_{1}=0,96 ; \mathrm{P}_{2}=1,68 ; \mathrm{P}_{3}=\right.$ 2,40 e; $\mathrm{P}_{4}=3,12$ g de $\mathrm{P} \mathrm{dm}^{-3}$ de solo), correspondendo respectivamente a 40; 70; 100; $130 \%$ da recomendação de adubação para a cultura da berinjela quando cultivada em vasos, sugerida por Malavolta (2006), acrescidos pelo uso de AR na irrigação das plantas. Aliado a esses tratamentos, adicionou-se uma testemunha cujas plantas receberam $100 \%$ da dose recomendada de $\mathrm{N}$ e $\mathrm{P}$, e foram irrigadas com água de abastecimento (AA); onde este tratamento foi comparado com os tratamentos que receberam a dose mínima (40\%) e a recomendada (100\%) da adubação com $\mathrm{N}$ e $\mathrm{P}$, e eram irrigados com AR. O delineamento experimental adotado foi $\mathrm{o}$ de blocos inteiramente casualizados, com os tratamentos arranjados em esquema fatorial $4 \times 4+1$, com quatro repetições, totalizando um estande final de 68 unidades experimentais.

Foi utilizada a cultivar de berinjela Embú, e para condução das plantas foram utilizados vasos plástico com 20 L de capacidade, preenchidos com $20 \mathrm{~kg}$ de material de solo, classificado como franco-arenoso, não salino e não sódico, sendo o material proveniente do município de Pombal, Paraíba.

As características químicas e físicas do solo utilizado (Tabela 1), foram determinadas conforme metodologias recomendadas pela Embrapa (1997).

Tabela 1. Atributos químicos e físicos do solo utilizado no experimento

\begin{tabular}{|c|c|c|c|c|c|c|c|c|c|c|c|c|}
\hline \multicolumn{13}{|c|}{ Atributos Químicos } \\
\hline \multirow{2}{*}{ pHes } & $\overline{\mathbf{K}^{+}}$ & $\mathrm{Na}$ & $\mathbf{C a}^{2}$ & $\mathrm{Mg}$ & $\mathrm{H}+\mathrm{Al}$ & $\mathrm{C}$ & \multirow{3}{*}{$\begin{array}{c}\mathbf{C E}_{\mathrm{es}} \\
\left(\mathbf{d m}^{-1}\right) \\
2,24\end{array}$} & $\mathbf{N}$ & $\mathrm{CO}$ & MO & \multirow{3}{*}{$\begin{array}{c}\text { SB } \\
\left({\left.\text { (cmolc } \mathbf{~ k g}^{-1}\right)}\right) \\
8,67\end{array}$} & \multirow{3}{*}{$\begin{array}{c}P_{\text {Ass }} \\
\text { (mg 100/g) } \\
4,61\end{array}$} \\
\hline & \multicolumn{6}{|c|}{$\left(\mathrm{cmol}_{\mathrm{c}} \mathrm{kg}^{-1}\right)$} & & \multicolumn{3}{|c|}{$\left(\mathrm{g} \mathrm{kg}^{-1}\right)$} & & \\
\hline 7,74 & 0,30 & 0,7 & 5,2 & 2,37 & 0,0 & 8,6 & & 0,5 & 5,4 & 9,3 & & \\
\hline \multicolumn{13}{|c|}{ Atributos Físicos } \\
\hline Areia & Sil & & Argila & \multirow{3}{*}{\multicolumn{2}{|c|}{$\begin{array}{c}\text { Porosidade } \\
\text { (\%) } \\
53,50 \\
\end{array}$}} & & DP & & & DS & \multirow{3}{*}{\multicolumn{2}{|c|}{$\begin{array}{c}\text { Água disponível } \\
\left(\mathrm{g} \mathrm{kg}^{-1}\right) \\
73,9\end{array}$}} \\
\hline \multirow{2}{*}{\multicolumn{4}{|c|}{$\left(\mathrm{g} \mathrm{kg}^{-1}\right)$}} & & & & & \multirow{2}{*}{\multicolumn{3}{|c|}{$\left(\mathrm{g} \mathrm{cm}^{-3}\right)$}} & & \\
\hline & & & 131,4 & & & & 2,71 & & & & & \\
\hline
\end{tabular}

* $\mathrm{p} \overline{\mathrm{es}}-\mathrm{pH}$ do extrato de saturação; $\mathrm{K}^{+}$- potássio; $\mathrm{Na}^{+}$- Sódio; $\mathrm{Ca}^{2+}$ - cálcio; $\mathrm{Mg}^{2+}$ - magnésio; $\mathrm{H}+\mathrm{Al}$ - hidrogênio + alumínio; CTC - capacidade de troca catiônica; $\mathrm{CE}_{\text {es }}$ - condutividade elétrica no extrato de saturação; $\mathrm{N}$ - nitrogênio; $\mathrm{CO}$ - carbono orgânico; MO - matéria orgânica; SB - Soma de bases; $\mathrm{P}_{\text {Ass. }}$ - fósforo assimilável; DP - densidade das partículas; DS - densidade do solo.

Após o acondicionamento nos vasos, o solo foi colocado em capacidade de campo, através do método de saturação por capilaridade, seguido por drenagem livre, utilizando os dois tipos de águas usadas na irrigação (residuária e de abastecimento), conforme os tratamentos.

As mudas de berinjela foram produzidas em bandejas de poliestireno expandido de 128 células, utilizando-se o substrato comercial a base de casca de pinus, húmus e vermiculita. Aos 25 dias após o semeio (DAS), foi realizado o transplantio de duas mudas por vaso, aos 17 dias após o transplantio (DAT), fez-se o desbaste deixando a planta com maior vigor. 
A fonte de $\mathrm{N}$ utilizada foi a ureia (45\% de $\mathrm{N}$ ), e para evitar possíveis perdas por volatilização e/ou lixiviação, a adubação nitrogenada foi parcelada em sete aplicações, sendo 2/7 aplicado em fundação e os 5/7 restantes, em adubação de cobertura a cada 7 DAT.

Como fonte de $\mathrm{P}$, utilizou-se superfosfato simples (18\% de $\left.\mathrm{P}_{2} \mathrm{O}_{5}\right)$, sendo incorporado como adubação de fundação cinco dias antes do transplantio. Foi realizada ainda, adubação potássica, na quantidade de 0,31 g $\mathrm{dm}^{-3}$, sendo o parcelamento ocorrido nos mesmos períodos em que ocorreram as adubações nitrogenadas.

Os tratos culturais realizados durante o ciclo da cultura foram, controle fitossanitário, principalmente de mosca-branca (Bemisia tabaci), com aplicações de $100 \mathrm{ml}$ do inseticida sistêmico Evidence ${ }^{\circledR} \quad 700$ WG (concentração $1 \mathrm{~g} \mathrm{~L}^{-1}$ ) no solo via água de irrigação. O controle de plantas espontâneas ocorreu sempre que necessário, utilizando-se de capinas manuais.

A AR utilizada no experimento foi proveniente de chuveiros, pias e mictórios dos banheiros localizados na UFCG, Campus de Pombal, coletada por tubulações e depositada em um tanque séptico, o qual, foi conectado por meio de um tubo inserido na extremidade inferior a um recipiente plástico com $500 \mathrm{~L}$ de capacidade, funcionando como reservatório de distribuição do efluente. Essa distribuição ocorreu por tubulações até os três filtros aeróbios com intermitências diferentes (cada filtro recebia $50 \mathrm{~L}$ de AR a cada 6, 8 e 12 horas). O efluente produzido foi armazenado em recipiente plástico com capacidade de 500 L. Os filtros foram construídos adaptando-se recipientes plásticos com capacidade de $250 \mathrm{~L}$ cada; na parte inferior dos recipientes continha uma camada de $10 \mathrm{~cm}$ de brita $\left(\mathrm{n}^{\circ} 1\right)$, seguida de $50 \mathrm{~cm}$ de areia e na parte superior mais uma camada de $5 \mathrm{~cm}$ de brita, para uniformizar o fluxo.

Na Tabela 2, encontram-se os valores médios dos parâmetros físico-químicos da AR antes e após o pós-tratamento com filtro de areia, conforme Sousa (2015). Os resultados da análise de qualidade da AR após o uso do filtro de areia, apresenta-se dentro dos padrões recomendado por Brasil (2005).

Tabela 2. Características físico-químicas da água residuária do tanque séptico e após os filtros de areia com fluxo intermitente

\begin{tabular}{|c|c|c|c|c|c|c|c|c|c|c|c|c|}
\hline \multicolumn{13}{|c|}{ AR do tanque séptico } \\
\hline \multirow[b]{2}{*}{ pH } & \multirow{2}{*}{$\begin{array}{c}\text { CEa } \\
\left(\begin{array}{c}\mathrm{dS} \mathrm{m}^{-} \\
1\end{array}\right)\end{array}$} & OD & Ca & Mg & $\mathrm{Cl}^{-}$ & $\mathbf{P}$ & $\mathbf{N}$ & $\mathrm{Na}$ & $\mathbf{K}$ & DQO & DBO & \multirow{2}{*}{$\begin{array}{c}\text { RAS } \\
\left(\begin{array}{c}\text { mmol } \\
\text { 1) }\end{array}\right.\end{array}$} \\
\hline & & \multicolumn{10}{|c|}{$\left(\mathrm{mg} \mathrm{L}^{-1}\right)$} & \\
\hline 8,3 & 0,82 & 0,4 & 34,4 & 25,4 & 102,5 & 0,89 & 0,0002 & 0,02 & 0,009 & 89,8 & 15,6 & 3,66 \\
\hline \multicolumn{13}{|c|}{ AR após os filtros de areia } \\
\hline \multirow[b]{2}{*}{ pH } & CEa & OD & Ca & Mg & $\mathrm{Cl}^{-}$ & $\mathbf{P}$ & $\mathbf{N}$ & $\mathrm{Na}$ & $\mathbf{K}$ & DQO & DBO & \multirow{2}{*}{$\begin{array}{c}\text { RAS } \\
\left(\mathrm{mmol}^{-} \mathbf{L}^{-}\right. \\
1)\end{array}$} \\
\hline & $\left(\mathrm{dS} \mathrm{m} \mathrm{m}^{-1}\right)$ & \multicolumn{10}{|c|}{$\left(\mathrm{mg} \mathrm{L}^{-1}\right)$} & \\
\hline 6,2 & 0,56 & 6,4 & 58,4 & 44,0 & 86,2 & 0,70 & 0,0001 & 0,01 & 0,010 & 127,3 & 25,4 & 1,39 \\
\hline
\end{tabular}

(potencial hidrogeniônico); CE - condutividade elétrica; OD - oxigênio dissolvido; Ca - cálcio; $\mathrm{Mg}$ - magnésio, $\mathrm{Cl}^{-}$cloretos; P - fósforo; $\mathrm{N}$ - nitrogênio; $\mathrm{Na}$ - sódio; $\mathrm{K}$ - potássio; DQO - demanda química de oxigênio; DBO - demanda bioquímica de oxigênio; RAS - relação de adsorção de sódio.

As avaliações de crescimento foram realizadas no início do florescimento (30 DAT). O crescimento das plantas de berinjela foi avaliado por meio da altura de planta (AP) em cm, mensurando-se a distância entre o colo da planta e o ápice da haste principal; o diâmetro caulinar (DC) em mm, determinado a $3 \mathrm{~cm}$ do colo das plantas com o auxílio de paquímetro digital; o número de folhas (NF), considerando-se apenas as folhas com no mínimo $50 \%$ de sua área fotossinteticamente ativa e a largura mínima de $1 \mathrm{~cm}$; e a área foliar (AF) em $\mathrm{cm}^{2}$, obtida segundo metodologia proposta por Maldaner et al. (2009).

Ao final do ciclo da cultura, foi obtido, a partir da planta coletada de cada vaso, o acúmulo de fitomassa das plantas. O material vegetal foi separado em caule e folhas, 
posteriormente, e utilizando-se de balança com precisão digital determinou-se a matéria verde do caule (MVC), separando caules e ramos; e matéria verde das folhas (MVF) em g. Na sequência, o material foi colocado em estufa de circulação de ar para secagem a $65^{\circ} \mathrm{C}$, até obtenção de massa constante, com posterior obtenção da matéria seca do caule (MSC) e das folhas (MSF) em g.

Os dados obtidos foram submetidos à análise de variância pelo teste $\mathrm{F}(\mathrm{p}<0,05)$, e no caso de significância realizou-se análise de regressão polinomial para desdobramento dos efeitos de doses de N e P. O teste de Tukey foi utilizado para comparar as médias dos tratamentos que foram irrigados com água de abastecimento e receberam a dose $100 \%$ de $\mathrm{N}$ e $\mathrm{P}$ conforme recomendação (Testemunha), com os que foram irrigados com água residuária e receberam 40\% (N1P1) e 100\% (N3P3) da recomendação de N e P. Para estas análises utilizou-se do software estatístico SISVAR (FERREIRA, 2014).

\section{RESULTADOS E DISCUSSÃO}

Conforme análise de variância para variáveis de crescimento da berinjeleira, a altura de planta (AP) foi influenciada de forma significativa pelas doses de $\mathrm{N}(\mathrm{p}<0,05)$. As doses de $\mathrm{P}$ influenciaram significativamente $\mathrm{o}$ número de folhas (NF) $(\mathrm{p}<0,05)$. Por outro lado, não foi constatada influência da interação entre os fatores estudados ( $\mathrm{N}$ x P). Quanto ao teste de comparação entre médias, observou-se que os diferentes tipos de água usada na irrigação das plantas (AR e AA) não influenciaram significativamente nenhuma das variáveis estudadas (Tabela 3). A ausência de efeito significativo sobre o diâmetro caulinar (DC) e a área foliar (AF), indica que a menor dose de $\mathrm{N}\left(0,22 \mathrm{~g} \mathrm{~N} \mathrm{dm}^{-3}\right)$ foi suficiente para garantir o crescimento em diâmetro do caule e maior expansão foliar das plantas.

Tabela 3. Resumo das análises de variância para as variáveis altura de plantas (AP), diâmetro caulinar (DC), número de folhas (NF) e área foliar (AF) da berinjeleira sob adubação nitrogenada e fosfatada, e teste de comparação de médias entre os tratamentos irrigados com água residuária (AR) e de abastecimento (AA)

\begin{tabular}{|c|c|c|c|c|c|}
\hline \multirow[b]{2}{*}{ Fonte de Variação } & \multirow[b]{2}{*}{ GL } & \multicolumn{4}{|c|}{ Quadrados Médios } \\
\hline & & AP & DC & NF & $\mathbf{A F}$ \\
\hline Nitrogênio (N) & 3 & $72,52^{*}$ & $1,34^{\mathrm{ns}}$ & $1,87^{\mathrm{ns}}$ & $7162734,7^{\mathrm{ns}}$ \\
\hline Regressão Linear & 1 & $30,19^{\text {ns }}$ & $1,87^{\mathrm{ns}}$ & $2,81^{\mathrm{ns}}$ & $9281319,3^{\mathrm{ns}}$ \\
\hline Regressão Quadrática & 1 & $146,10^{*}$ & $0,20^{\mathrm{ns}}$ & $1,56^{\mathrm{ns}}$ & $10086110,5^{\mathrm{ns}}$ \\
\hline Fósforo (P) & 3 & $24,22^{\mathrm{ns}}$ & $0,80^{\mathrm{ns}}$ & $12,20^{*}$ & $8399360,8^{\mathrm{ns}}$ \\
\hline Regressão Linear & 1 & $72,10^{\mathrm{ns}}$ & $0,91^{\text {ns }}$ & $19,01^{*}$ & $13461898,4^{\mathrm{ns}}$ \\
\hline Regressão Quadrática & 1 & $0,08^{\mathrm{ns}}$ & $0,00^{\mathrm{ns}}$ & $4,00^{\mathrm{ns}}$ & $9724020,9^{\mathrm{ns}}$ \\
\hline Interação (N x P) & 9 & $28,63^{\text {ns }}$ & $0,59^{\text {ns }}$ & $3,13^{\text {ns }}$ & $8313950,9^{\text {ns }}$ \\
\hline Blocos & 3 & 21,64 & 2,09 & 1,54 & 8551707,2 \\
\hline Resíduo & 45 & 20,96 & 0,78 & 4,48 & 8830218,9 \\
\hline C. V. (\%) & & 22,26 & 12,32 & 16,14 & 18,08 \\
\hline Tratamentos & & \multicolumn{4}{|c|}{ Médias } \\
\hline Testemunha (AA) & & $23,25 a$ & $8,57 a$ & $18,25 a$ & $1727,50 a$ \\
\hline N3P3 (AR) & & $18,25 a$ & $7,29 a$ & $12,25 a$ & $977,76 a$ \\
\hline N1P1 (AR) & & $14,37 \mathrm{a}$ & $7,37 a$ & $11,75 a$ & $1206,85 a$ \\
\hline
\end{tabular}

ns - não significativo, ${ }^{*}$ - significativo a 5\% (p <0,05) pelo teste F; GL - número de graus de liberdade; C. V. coeficiente de variação. Médias seguidas da mesma letra na coluna não diferem entre si pelo teste de Tukey ao nível de $5 \%$ de probabilidade $(\mathrm{p}<0,05)$. Testemunha $(\mathrm{AA})$ : plantas que receberam irrigação com água de abastecimento e $100 \%$ da recomendação de N e P; N3P3 (AR): plantas que receberam irrigação com água residuária e 100\% da recomendação de N e P; N1P1 (AR): plantas que receberam irrigação com água residuária e $40 \%$ da recomendação de N e P.

Pela análise de regressão apresentada na Figura 1A, as médias da variável AP sob os efeitos das doses de $\mathrm{N}$, apresentaram ajuste quadrático. Ao derivar a equação, foi 
verificado que a maior altura está associada à dose estimada de $0,43 \mathrm{~g}_{\text {de }} \mathrm{N} \mathrm{dm}^{-3}$, alcançando $23 \mathrm{~cm}$, proporcionando ganhos de 21,14\% quando comparado a dose máxima de $\mathrm{N}(0,72$ $\mathrm{g}$ de $\mathrm{N} \mathrm{dm}^{-3}$ ). Foi constatado também, reduções de $11,76 \%$ a partir do nível de $\mathrm{N}$ estimado. O $\mathrm{N}$ promove aumento do vigor da planta, o qual está associado á altura das mesmas (SOUZA et al., 2016; RAMOS et al., 2016), e quando fornecido em quantidades adequadas, esse nutriente promove acréscimos significativos sobre os estádios de crescimento e desenvolvimento das plantas, uma vez que, faz parte do seu metabolismo, através das enzimas,

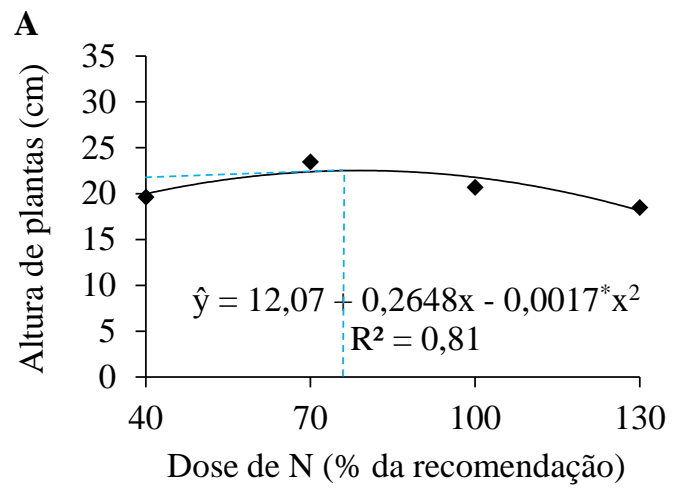

aminoácidos, proteínas, vitaminas, pigmentos e ácidos nucléicos, constituintes fundamentais do protoplasma e da clorofila, essenciais para a fotossíntese (ZHOU et al., 2011; SOUZA et al., 2017). Porém, aplicações de fertilizantes nitrogenados acima da quantidade requerida pelas plantas têm causado restrições no desenvolvimento das mesmas, já que promove efeito salino no solo, resultando em desbalanço nutricional (MEDEIROS et al., 2015). Desta forma, a dose estimada $\left(0,47 \mathrm{~g}\right.$ de $\left.\mathrm{N} \mathrm{dm}^{-3}\right)$ promoveu maior crescimento das plantas, o qual, é a matéria seca acumulada ao longo do tempo, e representa a fotossíntese líquida.

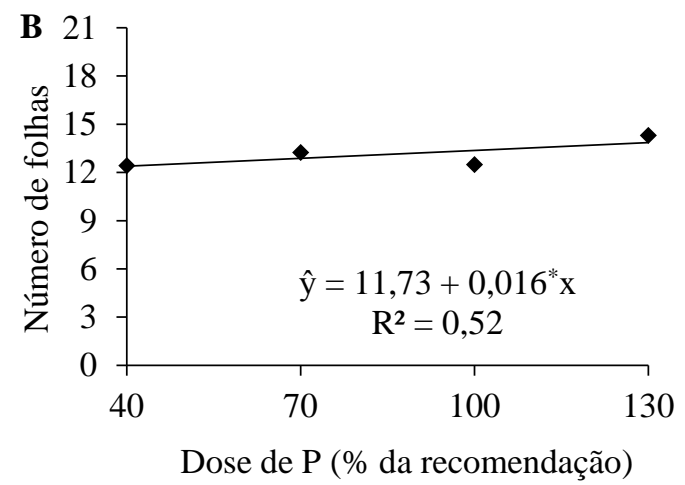

Figura 1. Altura de plantas sob doses de nitrogênio (A) e número de folhas em função das doses de fósforo (B) de plantas de berinjela cv. Embú irrigadas com água residuária.

Outros autores Zhou et al. (2011), Aragão et al. (2012), Araújo et al. (2012), Guedes Filho et al. (2013), Abrantes (2014), Medeiros et al. (2015), Ramos et al. (2016), também observaram reduções na AP de várias culturas agrícolas sob excesso de adubação nitrogenada.

Os aumentos verificados até a dose ótima de $\mathrm{N}$, podem estarem relacionados com o maior crescimento da área foliar, do sistema radicular e da relação entre área foliar e fotossíntese, devido às funções desse elemento no metabolismo das plantas, o qual atua como constituinte da molécula de clorofila, ácidos nucléicos, aminoácidos e proteínas, influenciando a divisão, expansão celular e a fotossíntese (GUEDES FILHO et al., 2013; VIEIRA et al., 2016), resultando em aumento da altura das plantas.

Já as reduções verificadas sobre as doses acima do ponto de inflexão, observado neste experimento, ocorreram devido à acidificação do meio, uma vez que, o adubo fornecido as plantas foi a ureia, cujo desdobramento pela uréase libera $\mathrm{H}^{+}$(VIEIRA et al., 2016), causando assim, o excesso de $\mathrm{N}$ no solo, ocasionado pela adubação nitrogenada junto com o uso da $A R$, promovendo danos às plantas, principalmente o desequilíbrio em relação aos outros nutrientes (ARAGÃO et al., 2012; LIMA et al., 2014). Denota-se que o a acidificação do meio, pode ter ocorrido também devido ao teor de sais na AR, podendo estar relacionado com as concentrações dos macronutrientes na água, já que o $\mathrm{N}$ e $\mathrm{P}$ estão dissolvidos em maiores quantidades nos efluentes (MEDEIROS et al., 2015; NASCIMENTO et al., 2016). Dessa forma, as doses aplicadas junto com a quantidade de nutrientes presente na $\mathrm{AR}$, promoveram efeito fitotóxico.

Os relatos de Araújo et al. (2012), confirmam os resultados deste trabalho. Esses autores afirmam que, doses excessivas de $\mathrm{N}$ 
promovem reduções no crescimento ou desenvolvimento das plantas, possivelmente pelo efeito tóxico e/ou salino causado pelo excesso desse elemento no solo, especialmente quando é aplicado na forma de ureia. Outrossim, o excesso de $\mathrm{N}$ pode prolongar o ciclo vegetativo da planta e atrasar a floração, também pode causar danos oxidativos que comprometem importantes componentes celulares, como lipídios, proteínas, DNA, RNA, reduzindo o crescimento e o rendimento vegetal da cultura (ZHOU et al., 2011; RAMOS et al., 2016; SOUZA et al., 2017).

O NF das plantas de berinjela foi influenciado positivamente pelas doses crescentes de $\mathrm{P}$, conforme a regressão (Figura $1 \mathrm{~B})$, houve acréscimo linear no NF na ordem de $0,13 \%$ por aumento unitário da dose de $\mathrm{P}$ aplicada, ou seja, aumento de $12,3 \%$ no NF das plantas sob dose máxima de $\mathrm{P}\left(3,12 \mathrm{~g} \mathrm{dm}^{-3}\right)$ em comparação as plantas que receberam a dose mínima $\left(0,96 \mathrm{~g}\right.$ de $\left.\mathrm{P} \mathrm{dm}^{-3}\right)$. Estes resultados divergem dos encontrados por Manfio (2007), analisando o rendimento da berinjela em função de doses de $\mathrm{P}_{2} \mathrm{O}_{5}$. Esse autor não encontrou resposta significativa quanto à aplicação de doses crescentes de $\mathrm{P}$ sobre o NF das plantas aos 30 DAT.

Os aumentos do NF encontrado com as maiores doses de $\mathrm{P}$, provavelmente estão associados às múltiplas reações desse elemento na planta, através do processo de transferência de energia, já que, compõe a molécula de Trifosfato de Adenosina (ATP) (MANFIO, 2007; MEDEIROS et al., 2015). O P também está presente em membranas biológicas, na respiração e armazenamento de energia na fotossíntese, o qual é utilizado na forma de ATP.

Os resultados encontrados neste trabalho para o NF divergem dos relatos de Medeiros et al. (2015) e Nascimento et al. (2016), quando afirmam que, as exigências nutricionais das culturas podem ser supridas pelos nutrientes presentes na própria água residuária, possibilitando reduções nas aplicações de fertilizantes sintéticos.

Com base nos resultados da análise de variância (Tabela 4), observa-se influência significativa $(\mathrm{p}<0,01)$ das doses de $\mathrm{N}$ sobre todas as variáveis de acúmulo de fitomassa estudadas. Quanto ao fator doses de $\mathrm{P}$ e a interação entre os fatores estudados ( $\mathrm{N} \mathrm{x} \mathrm{P)}$, não foi observado influência sobre as variáveis avaliadas. Com relação ao teste de comparação entre médias, foi constatado que AR usada na irrigação das plantas influenciou significativamente a matéria verde de folhas (MVF), e a matéria seca do caule (MSC) e de folhas (MSF). Os resultados obtidos neste estudo concordam com os encontrados por diversos autores como Alves et al. (2009) e Nobre et al. (2010), ao estudarem o efeito da irrigação com AR e aplicação de $\mathrm{N}$ sobre a fitomassa produzida em outras culturas. Conforme Sousa Neto et al. (2012), quando utiliza AR tratada na agricultura irrigada, ocorrem melhorias no crescimento e desenvolvimento das plantas, provavelmente, devido a AR tratada promover um aporte de nutrientes, ocasionando reduções da necessidade de fertilizantes sintéticos.

Tabela 4. Resumo das análises de variância das variáveis matéria verde do caule (MVC) e folhas (MVF), matéria seca do caule (MSC) e folhas (MSF) de plantas de berinjela (Solanum melongena L.) sob doses de nitrogênio e fósforo e Teste de comparação de médias entre os tratamentos irrigados com água residuária (AR) e de abastecimento (AA)

\begin{tabular}{lccccc}
\hline & & \multicolumn{4}{c}{ Quadrados Médios } \\
\cline { 4 - 6 } Fonte de Variação & GL & MVC & MVF & MSC & MSF \\
\hline Nitrogênio (N) & 3 & $13717,58^{* *}$ & $9758,87^{* *}$ & $4586,96^{* *}$ & $4411,04^{* *}$ \\
Regressão Linear & 1 & $1749,43^{\text {ns }}$ & $703,71^{\text {ns }}$ & $1879,61^{\text {ns }}$ & $1449,08^{\text {ns }}$ \\
Regressão Quadrática & 1 & $34121,01^{* *}$ & $26349,40^{* *}$ & $10060,34^{* *}$ & $8911,36^{* *}$ \\
Fósforo (P) & 3 & $28,55^{\text {ns }}$ & $33,67^{\text {ns }}$ & $8,23^{\text {ns }}$ & $19,30^{\text {ns }}$ \\
Regressão Linear & 1 & $0,01^{\text {ns }}$ & $97,54^{\text {ns }}$ & $1,03^{\text {ns }}$ & $25,50^{\text {ns }}$ \\
Regressão Quadrática & 1 & $83,28^{\text {ns }}$ & $14,40^{\text {ns }}$ & $21,14^{\text {ns }}$ & $30,30^{\text {ns }}$ \\
Interação (N x P) & 9 & $9,94^{\text {ns }}$ & $133,19^{\text {ns }}$ & $6,27^{\text {ns }}$ & $14,97^{\text {ns }}$
\end{tabular}




\begin{tabular}{lccccc} 
Blocos & 3 & 47,39 & 242,94 & 12,79 & 0,72 \\
Resíduo & 45 & 36,47 & 67,78 & 16,30 & 9,85 \\
\hline C. V. (\%) & \multicolumn{1}{c}{ Tratamentos } & 1,87 & 4,79 & 5,17 & 4,05 \\
\hline \multicolumn{1}{c}{ N3P3 (AR) } & & \multicolumn{4}{c}{ Médias } \\
\hline N1P1 (AR) & & $328,89 \mathrm{a}$ & $179,66 \mathrm{a}$ & $82,59 \mathrm{a}$ & $77,13 \mathrm{a}$ \\
Testemunha (AA) & & $303,09 \mathrm{a}$ & $138,90 \mathrm{~b}$ & $70,31 \mathrm{~b}$ & $69,49 \mathrm{ab}$ \\
\hline
\end{tabular}

ns - não significativo, ${ }^{* *}$ - significativo a $1 \%(\mathrm{p}<0,01)$ pelo teste F; GL - número de graus de liberdade; C. V. coeficiente de variação. Médias seguidas da mesma letra na coluna não diferem entre si pelo teste de Tukey ao nível de $5 \%$ de probabilidade ( $<<0,05)$. Testemunha $(\mathrm{AA})$ : plantas que receberam irrigação com água de abastecimento e 100\% da recomendação de N e P; N3P3 (AR): plantas que receberam irrigação com água residuária e 100\% da recomendação de N e P; N1P1 (AR): plantas que receberam irrigação com água residuária e $40 \%$ da recomendação de $\mathrm{N}$ e $\mathrm{P}$.

A MVC e MVF da berinjeleira, foram significativamente influenciadas pelo aumento das doses de $\mathrm{N}$ e, conforme as equações de regressão (Figura 2A e 2B) observa-se haver resposta quadrática, sendo estimada a produção máxima de MVC (352 g) e MVF (161 g) ao fornecer às plantas as doses estimadas de 0,45 e $047 \mathrm{~g}$ de $\mathrm{N} \mathrm{dm}{ }^{-3}$, respectivamente, apresentando a partir deste nível de $\mathrm{N}$, a tendência de decréscimo dessas variáveis.

Os aumentos observados na MVC e MVF, em decorrência do aumento das doses de $\mathrm{N}$ até os limites ótimos, estão relacionados possivelmente, a maximização da capacidade fotossintética ocorrido nas plantas decorrentes da atuação deste nutriente, uma vez que, esse elemento atua como um dos principais componentes da célula vegetal, incluindo aminoácidos, ácidos nucléicos, clorofila, proteínas (GUEDES FILHO et al., 2013; LIMA et al., 2014; SOUZA et al., 2016). Já as reduções observadas a partir dos limites ótimos de $\mathrm{N}$, pode estar relacionado ao excesso desse elemento no solo, causando uma possível toxicidade durante a assimilação excessiva desse elemento, como também ao provável desequilíbrio nutricional, em virtude do desbalanceamento dos nutrientes essenciais aos processos metabólicos das plantas ( ARAÚJO et al., 2012; $\quad$ LIMA et al., 2015; RAMOS et al., 2016). Esses resultados corroboram com os obtidos por Alves et al. (2009), Nobre et al. (2010), Andrade et al. (2012) e Santos et al. (2016) quando avaliaram $\mathrm{o}$ uso de $\mathrm{N}$ e AR em outras culturas agrícolas.

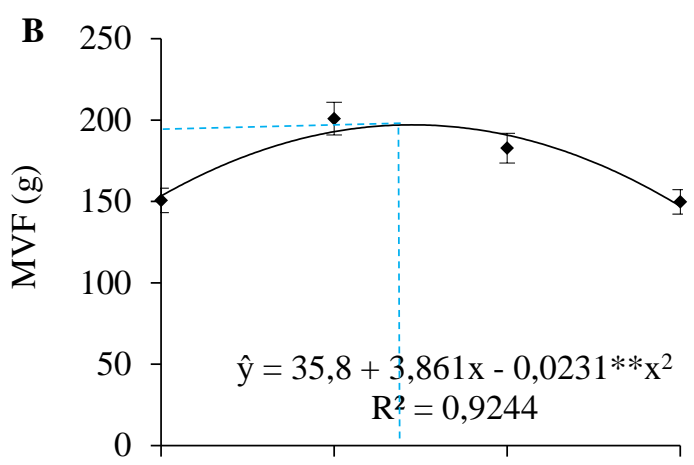



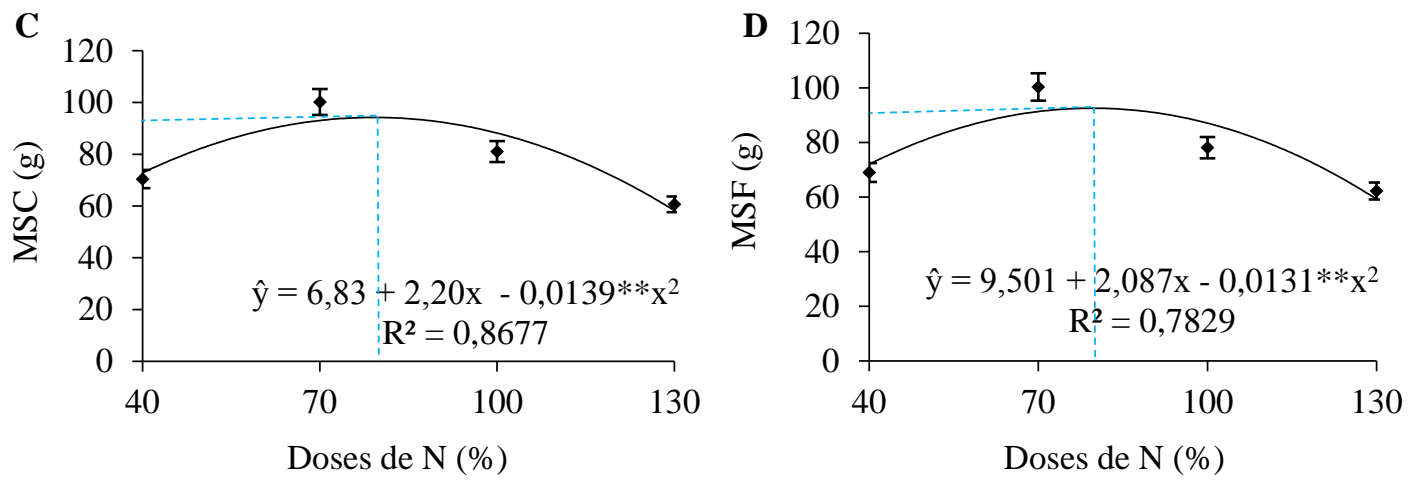

Figura 2. Matéria verde de caule (A) e folhas (B), Matéria seca de caule (C) e folhas (D) de plantas de berinjela cv. Embú irrigadas com água residuária e doses crescentes de nitrogênio.

Acompanhando a mesma tendência observada para a MVC e MVF, pode-se notar que, a MSC e MSF também se ajustaram ao modelo de regressão quadrático (Figura 2C e 2D), sendo estimada a produção máxima de MSC (95 g) e MSF (93 g) quando as plantas receberam $0,44 \mathrm{~g}$ de $\mathrm{N} \mathrm{dm}{ }^{-3}$, ocorrendo reduções dessas variáveis nas doses acima desse valor. Os aumentos observados até os limites ótimos e as reduções ocorridas com as doses acima desse valor, já eram esperados em consequência deste comportamento já ter ocorrido para a MVC e MVF. Esses resultados assemelham-se aos obtidos por vários autores Nobre et al. (2010), Andrade et al. (2012), Sousa Neto et al. (2012), Oliveira et al. (2013), quando avaliaram em outras culturas a irrigação com AR e doses de $\mathrm{N}$ sobre a matéria seca das plantas.

Como citado anteriormente, os aumentos observados ocorreram devido à atuação do $\mathrm{N}$ em múltiplas funções estruturais e de constituintes celulares, que estão intimamente relacionados com a ativação de muitas enzimas, além da sua participação nos processos essenciais das plantas, como fotossíntese, respiração, influência na taxa de expansão, diferenciação celular e síntese de proteína (SANTOS et al., 2016; SOUZA et al., 2017). Já os resultados de decréscimos obtidos com doses acima do limite ótimo, provavelmente, estão relacionados com grande quantidade de $\mathrm{N}$ no solo, uma vez que os excessos de adubos nitrogenados podem ocasionar o desequilíbrio nutricional, principalmente quando são fornecidos na forma de ureia (ARAÚJO et al., 2012), predispondo nas plantas alterações de crescimento, retardo na senescência, mudanças na morfologia e fisiologia (ABRANTES, 2014; SANTOS et al., 2016; SOUZA et al., 2017).

Os resultados obtidos neste experimento com água residuária, podem evidenciar um suprimento adequado de $\mathrm{N}$ às plantas, assim, a eficiência desse nutriente pode ser maximizada ao ser usado a dose adequada, onde ocorrerão reduções nas aplicações de fertilizantes sintéticos e, consequentemente, reduzem-se os danos ambientais, além de aumentar a eficiência das culturas.

\section{CONCLUSÕES}

A interação entre as doses de nitrogênio e fósforo não influenciou os aspectos de crescimento e acúmulo de fitomassa da berinjeleira.

O aumento unitário das doses de fósforo promoveu acréscimos de $0,13 \%$ no número de folhas da berinjela quando irrigada com água residuária.

A dose estimada de nitrogênio de $0,43 \mathrm{~g}$ $\mathrm{dm}^{-3}$ e irrigação com água residuária resultou em maior altura de plantas.

As maiores doses de nitrogênio promoveram decréscimos significativos sobre as trocas gasosas e acúmulo de fitomassa da berinjeleira. 
ABRANTES, E. G. de. Influência do silício na nutrição nitrogenada da berinjela. 2014. 73 f. Dissertação (Mestrado em Horticultura Tropical) - Universidade Federal de Campina Grande, Pombal.

ALVES, W. W. A.; AZEVEDO, C. A. V.; DANTAS NETO, J.; SOUSA, J. T.; LIMA, V. L. A. Águas residuárias e nitrogênio: efeito na cultura do algodão marrom. Revista verde de Agroecologia e Desenvolvimento Sustentável, v. 4, n. 1, p. 16-23, 2009.

ANDRADE, L. O.; GHEYI, H. R.; NOBRE, R. G.; DIAS, N. S.; NASCIMENTO, E. C. S. Crescimento de girassóis ornamental em sistema de produção orgânica e irrigada com água residuária tratada. Irriga, v. 1, Edição Especial, p. 69-82, 2012.

ARAGÃO, V. F.; FERNANDES, P. D.; GOMES FILHO, R. R.; CARVALHO, C. M. de; FEITOSA, H. de O.; FEITOSA, E. de O. Produção e eficiência no uso de água do pimentão submetido a diferentes lâminas de irrigação e níveis de nitrogênio. Revista Brasileira de Agricultura Irrigada, v. 6, n. 3, p. 207-216, 2012.

ARAÚJO, J. L.; FAQUIN, V.; VIEIRA, N. M. B.; OLIVEIRA, M. V. C.; SOARES, A. A.; RODRIGUES, C. R.; MESQUITA, A. C. Crescimento e produção do arroz sob diferentes proporções de nitrato e de amônio. Revista Brasileira de Ciência do Solo, v. 36, n. 3, p. 921-930, 2012.

BRASIL, Distrito Federal, Brasília. Resolução n ${ }^{\circ} 357$ de 17 de março de 2005. Conselho Nacional do Meio Ambiente - CONAMA. Diário Oficial da República Federativa do Brasil, $2005 . \quad 23 p . \quad$ Disponível em: http://www.mma.gov.br/port/conama/legiabre .cfm?codlegi=459. Acesso em: 05 mar. 2017.

EMBRAPA. Manual de métodos de análise de solo. 2. ed. Rio de Janeiro: Centro Nacional de Pesquisa de Solos, 1997. 212 p.
FERREIRA, D. F. SISVAR: A guide for its bootstrap procedures in multiple comparisons. Ciência e Agrotecnologia, v. 38, n. 2, p. 109112, 2014.

FILGUEIRA, F. A. R. Novo manual de olericultura: agrotecnologia moderna, produção e comercialização de hortaliças. 2 . ed. Viçosa: UFV, 2008. 421 p.

GUEDES FILHO; D. H.; SANTOS, J. B. dos; GHEYI, H. R.; CAVALCANTE, L. F.; FARIAS, H. L. de. Biometria do girassol em função da salinidade da água de irrigação e da adubação nitrogenada. Revista Brasileira de Agricultura Irrigada, v. 7, n. 5, p. 277-289, 2013.

LIMA, G. S.; NOBRE, R. G.; GHEYI, H. R.; SOARES, L. A. A.; LOURENÇO, G. S.; SILVA, S. S. Aspectos de crescimento e produção da mamoneira irrigada com águas salinas e adubação nitrogenada. Revista Brasileira de Engenharia Agrícola e Ambiental, v. 18, n. 6, p. 615-622, 2014.

LIMA, L. A.; OLIVEIRA, F. A.; ALVES, R. C.; LINHARES, P. S. F.; MEDEIROS, A. M. A.; BEZERRA, F. M. S. Tolerância da berinjela à salinidade da água de irrigação. Revista Agro@mbiente On-line, v. 9, n. 1, p. 27-34, 2015.

MALAVOLTA, E. Manual de nutrição mineral de plantas. São Paulo: CERES, 2006. $638 \mathrm{p}$.

MALDANER, I. C.; GUSE, F. I.; STRECK, N. A.; HELDWEIN, A. B.; LUCAS, D. D. P.; LOOSE, L. H. Filocrono, área foliar e produtividade de frutos de berinjela conduzidas com uma e duas hastes por planta em estufa plástica. Ciência Rural, v. 39, n. 3, p. 671-677, 2009.

MANFIO, M. Rendimento da Berinjela em função de doses de $\mathbf{P}_{2} \mathbf{O}_{5}$. 2007. $53 \mathrm{f}$. Dissertação (Mestrado em Agronomia Agricultura Tropical) - Universidade Federal da Paraíba, Areia. 
MEDEIROS, A. S.; NOBRE, R. G.; FERREIRA, E. S.; ARAÚJO, W. L.; QUEIROZ, M. M. F. Crescimento inicial da berinjeleira sob adubação nitrogenada e fosfatada e irrigada com água de reuso. Revista verde de Agroecologia e Desenvolvimento Sustentável, v. 10, n. 3, p. 34-40, 2015.

NASCIMENTO, T. S.; MONTEIRO, R. N. F.; SALES, M. A. DE L.; FLORIANO, L. S.; PEREIRA, A. I. de A. Irrigação com efluente de piscicultura no cultivo de mudas de tomate. Revista Brasileira de Agricultura Irrigada, v. 10, n. 4, p. 866-874, 2016.

NOBRE, R. G.; GHEYI, H. R.; SOARES, F. A. L.; ANDRADE, L. O.; NASCIMENTO, E. C. S. Produção do girassol sob diferentes lâminas com efluentes domésticos e adubação orgânica. Revista Brasileira de Engenharia Agrícola e Ambiental, v. 14, n. 7, p. 747-754, 2010.

OLIVEIRA, F. A.; DUARTE, S. N.; MEDEIROS, J. F.; DIAS, N. S.; SILVA, R. C. P.; LIMA, C. J. G. Manejos da fertirrigação e doses de $\mathrm{N}$ e $\mathrm{K}$ no cultivo de pimentão em ambiente protegido. Revista Brasileira de Engenharia Agrícola e Ambiental, v. 17, n. 11, p. 1152-1159, 2013.

OLIVEIRA, F. A.; MEDEIROS, J. F.; ALVES, R. C.; LINHARES, P. S. F.; MEDEIROS, A. M. A.; OLIVEIRA, M. K. T. Interação entre salinidade da água de irrigação e adubação nitrogenada na cultura da berinjela. Revista Brasileira de Engenharia Agrícola e Ambiental, v. 18, n. 5, p. 480-486, 2014.

RAMOS, J. P.; ANDRIOLO, J. L.; BALARDIN, R. S.; MARQUES, L. N.; SERAFINI, P. T.; STEFANELLO, M. T. Nitrogen doses on soybean growth and Asian rust progress in two cultivars. Comunicata Scientiae, v. 7, n. 4, p. 440-449, 2016.

SANTOS, J. B.; GHEYI, H. R.; LIMA, G. S.; XAVIER, D. A.; CAVALCANTE, L. F.; CENTENO, C. R. M. Morfofisiologia e produção do algodoeiro herbáceo irrigado com guas salinas e adubado com nitrogênio. Comunicata Scientiae, v. 7, n. 1, p. 86-96, 2016.

SOUSA NETO, O. N.; ANDRADE FILHO, J.; DIAS, N. S.; REBOUÇAS, J. R. L.; OLIVEIRA, F. R. A.; DINIZ, A. A. Fertigação do algodoeiro utilizando efluente doméstico tratado. Revista Brasileira de Engenharia Agrícola e Ambiental, v. 16, n. 2, p. 200-208, 2012.

SOUSA, E. P. Qualidade físico-química e microbiológica de água residuária doméstica pós-tratada em fluxo descendente intermitente. 2015. 90 f. Dissertação (Mestrado Profissional em Sistemas Agroindustriais) - Universidade Federal de Campina Grande, Pombal.

SOUZA, Á. H. C.; REZENDE, R.; LORENZONI, M. Z.; SERON, C. C.; HACHMANN, T. L.; LOZANO, C. S. Response of eggplant crop fertigated with doses of nitrogen and potassium. Revista Brasileira de Engenharia Agrícola e Ambiental, v. 21, n. 1, p. 21-26, 2017.

SOUZA, L. P., NOBRE, R. G., SILVA, E. M., LIMA, G. S., PINHEIRO, F. W. A., ALMEIDA, L. L. S. Formation of 'Crioula' guava rootstock under saline water irrigation and nitrogen doses. Revista Brasileira de Engenharia Agrícola e Ambiental, v. 20, n. 8, p. 739-745, 2016.

VIEIRA, I. G. S.; NOBRE, R. G.; DIAS, A. S.; PINHEIRO, F. W. A. Cultivation of cherry tomato under irrigation with saline water and nitrogen fertilization. Revista Brasileira de Engenharia Agrícola e Ambiental, v. 20, n. 1, p. 55-61, 2016.

ZHOU, Y. H.; ZHANG, Y.; WANG, X.; CUI, J.; XIA, X.; SHI, K.; YU, J. Effects of nitrogen form on growth, $\mathrm{CO}_{2}$ assimilation, chlorophyll fluorescence, and photosynthetic electron allocation in cucumber and rice plants. Biomedicine \& Biotechnology, v. 12, n. 2, p. 126-134, 2011. 